\title{
DESIGN AND CONSTRUCTION OF A STREET SWEEPING MACHINE
}

\author{
Dr. Adedeji, Kasali Aderinmoye \\ Doctor, Department of Mechanical Engineering, \\ Lagos State University, Epe campus, Lagos State, Nigeria. \\ Engr. Adebesin, Akeem Adekunle \\ Research Scholar, Department of Mechanical Engineering, \\ The Federal Polytechnic, Ilaro, Ogun State, Nigeria
}

\begin{abstract}
Achieving World Health Organization (WHO) goal in combating COVID 19 pandemic infers an imperative to urgently increase our level of personal hygiene and environmental cleanliness. However, concerns have risen that increase in personal hygiene and social distancing have not kept pace with increase in the number of infected people. In this paper, a portable sweeping machine was developed from locally sourced raw materials to sweep and clean public places like markets, parks and gardens etc. as part of the measures to prevent further spread of the disease in public places. This machine simulates the traditional method of sweeping public places using brooms and parker. The bristles, Teflon and mild steel were subjected to various manufacturing processes and techniques. The machine was powered by a portable gasoline engine using a direct drive. Sprocket and chain arrangement transmitted the power to the Teflon drum for the required sweeping action. The results of the performance tests carried out showed that the machine sweeping efficiency increased with the increase in the energy input and speed. The comparison between the developed mechanical street sweepers and hand- held broom sweeping on street, parks, market and major roads, showed significant improvement in time taken, swept area, output energy and their corresponding efficiencies.
\end{abstract}

Keywords: Covid 19, social distancing, markets, machine speed, wastes, broom

\section{INTRODUCTION}

COVID 19 pandemic is a global threat to human lives as it poses danger to the world economic activities with its toll effect on the sharp drop in Gross Domestic Product [GDP] and external reserves. Several measures such as the use of hand sanitizer, social distancing, disinfection of markets and other public places are all geared towards reducing the world mortality rate. Sweeping has been a very essential part of housekeeping and it is an age long practice of cleaning garbage, refuse, dirt, dust, rubbish and unwanted materials away from our environments so as to make our immediate environment attractive and adorning to look and to prevent diseases[Prichard 2009]. Every home has some sort of broom or other sweeping products that are used to clean up our houses, backyards, farms and just almost any place. It is interestingly to know that the various kinds of brooms that we are using today evolved from something that has been here for a really long time, long or short brooms were usually used to sweep markets, parks, rooms, passages, corridors and streets but recently, the culture of housekeeping has been extended to our major roads and streets with the advent of street sweeping machines.[Aluko, 2011]

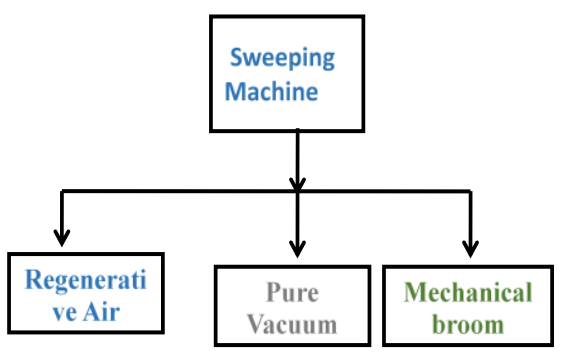

Fig 1: Sweeping Machine Concept Flow Chart

The regenerative air sweeper is closed looped air stream with no venting or fumes, ordinarily utilized for metropolitan application on avenues, parking areas and back roads. It is the most flexible innovation for getting ordinary road trash like overwhelming earth, rocks, sand leaves and whip. Regenerative air sweepers employ a closed-loop "cyclonic effect" to clean. They are similar to vacuum sweepers in that there is a similar vacuum inlet located on one side of the sweeping head. Unlike vacuum machines, however, regenerative air sweepers constantly re-circulate (regenerate) their air supply internally 


\section{International Journal of Engineering Applied Sciences and Technology, 2020 \\ Vol. 5, Issue 2, ISSN No. 2455-2143, Pages 626-630 \\ Published Online June 2020 in IJEAST (http://www.ijeast.com)}

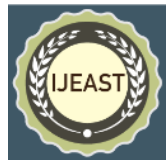

Mechanical Broom Sweepers: The technology behind this may be likened to cleaning with a broom and a parker, mechanical broom sweepers have a main drum-like broom that runs transversely-from one side of the sweeper to the other such that the broom bristles contact the paved surface covering the full width of the sweeper unit. Swept debris is collected into an attached refuse collector / bucket for onward delivery into the dumpsite.

Vacuum Sweepers: This might be compared to a family vacuum framework. A motor powers the blow that makes the required vacuum and suction pressure.

High-Efficiency Sweeper is a relatively new technology. It employs various fugitive dust loss controls and includes a variety of different types of machines such as vacuum, regenerative air, and one known mechanical broom machine. These machines not only remove a high level of accumulated material of all sizes (but especially smallmicron material less than 60 microns), but also are designed to control fugitive dust losses.

Ismaila,[2011] argued that litters in public places like markets, garages, parks and gardens and streets usually comprises of leaves, nylons, papers, small and medium size polluted particles from vehicles and different kinds of rubbish deposited by pedestrians and vehicle occupants. It is imperative to clear the road on standard premise because of open public hygiene and aesthetic purposes. Street sweeping is usually carried out by lorry driven type vehicle which include a twin gutter brushes that sweep the debris that litters the street nooks and crannies and then vacuumed the debris into refuse collector, taking into account that about $80 \%$ street wastes are located on the sides of the road [Parker, 2012].

\section{LITERATURE REVIEW}

John [1911] pictured a street sweeper which could be motor driven. He then acquired two silent partners: Daniel and Charles The trio began the development of his ideas; this is what culminated into the known Elgin sweeper company today. Several successful research works, advancement and experimentation were conducted thereby leading to the emergence of a motorized sweeper.

Stone and Marsalek [1996] affirmed that the efficiency of modern street sweeping equipment in collecting fine materials from the street surface has greatly improved with the most modern equipment being capable of collecting micro sized particles, and the overall collection efficiency in controlled (Indoor) tests as high as 95\% and only slightly lower (92\% in the case of freshly dispensed street sweeping in a $1 \mathrm{~m}$ swath on a street surface.

Hendrickson [1999] developed Eagle sweeper that sweep street using water as a means of its dust suppression system. It has in built water tanker with spraying nozzles but the disadvantage of this design is that when water is exhausted, it has to suspend sweeping so as to refill thus giving room for sweeping downtime, water conservation is another shortcoming of this machine.

Rokas [2000] developed a regenerative air system sweeper. This sweeper has both water nozzle and air flow direction and velocity. This sweeper has both water spout and wind current bearing and speed that make it to conserve water used in dusting while providing excellent dust control.

Amatos [2010] affirmed that the development of high efficiency street sweepers was on the increase. The percent of total solids removal may increase from $30-70+$ $\%$ with their associated operation frequencies approximately monthly to bi- weekly and varied depending upon land use or degree of littering the street.

Crockett [2014] modelled and developed waterless street sweeper for use in cold climate region. It is considered suitable in cold climates due to its environmentally friendly attributes, combined with the ability to perform year round sweeping to its naturally amicable characteristics, consolidated with the capacity to perform year round clearing without the wry of frozen tanks.

Al - Khatib[2015] developed a vacuum sweeper after observing broom sweeping method and discover that vacuum will do a better job at picking up fine grained particulates (silts, fine sands) in addition to coarse materials (sand and gravel) and debris make a superior showing with regards to with getting fine grained particulates (sediments, fine sands) notwithstanding coarse materials (sand and rock) and flotsam and jetsam

Breault [2005] observed that sweeping equipment may also produce some solids by surface attrition, as noted by German and Svensson [2002] in an experiment using an industrial brush vacuum sweeper when applied on sites with low solid accumulation.

\section{MATERIALS AND METHODS}

The analysis of the data for the research study as well as the methods, manufacturing procedures and the basis for material selected for the street sweeping machine developed are considered. This research follows simple engineering design phases, the approaches are: materials, design criteria, design calculations, aesthetic consideration, ergonomic consideration, safety design, design documentation, fabrication of the machine and cost evaluation.

The materials selected for the developed street sweeping machine were based on the strength, weight, machinability, availability and cost. The basic component parts are made from mild steel and rubber materials which are readily available locally. Other materials were selected for the design based on strength, rigidity, toughness, resilience, frictional properties and hardness. 


\section{Design Characteristics}

When designing the machine, the listed criteria define a successful match between the products and users:

1. Human factor

2. Functional requirements

3. Ease to use

4. Health and Safety

5. Quality of working life.

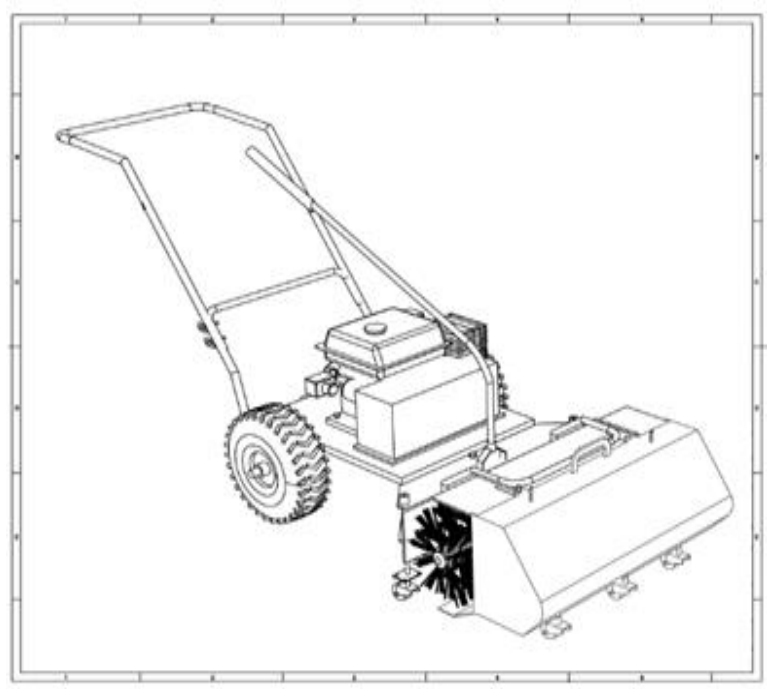

Figure2: Assembly drawing of the Sweeping Machine

\section{RESULTS AND DISCUSSION}

The results obtained during the pilot test conducted to evaluate the performance of the developed street sweeping machine of $7.5 \mathrm{hp}$ Gasoline Engine is shown in Table 1, Table 2 gives the Values of swept area by a Street Sweeper Fig 3 presents the Swept Area against Energy Consumed, Fig 3 depicts the Swept Area against time taken 7.5h.p Gasoline Engine and Fig 5shows the Swept Area against Time taken- Hand held broom.

Table 1: Values of 7.5h.p Gasoline Engine

\begin{tabular}{|c|c|c|c|c|}
\hline $\begin{array}{c}\text { Length } \\
(\mathrm{m})\end{array}$ & $\begin{array}{c}\text { Breadth } \\
(\mathrm{m})\end{array}$ & $\begin{array}{l}\text { Swept } \\
\text { Area } \\
\left(\mathrm{m}^{2}\right)\end{array}$ & $\begin{array}{l}\text { Time } \\
\text { Taken } \\
(\mathrm{s})\end{array}$ & $\begin{array}{l}\text { Energy } \\
\text { Consumed } \\
(\mathrm{J})\end{array}$ \\
\hline 1 & 0.6 & 0.6 & 3.0 & 1980 \\
\hline 2 & 0.6 & 1.2 & 6.0 & 3960 \\
\hline 3 & 0.6 & 1.8 & 9.0 & 5940 \\
\hline 4 & 0.6 & 2.4 & 12.0 & 7920 \\
\hline 5 & 0.6 & 3.0 & 16.0 & 9900 \\
\hline 6 & 0.6 & 3.6 & 19.0 & 11880 \\
\hline 7 & 0.6 & 4.2 & 21.0 & 13860 \\
\hline 8 & 0.6 & 4.8 & 24.0 & 15840 \\
\hline 9 & 0.6 & 5.4 & 28.0 & 17820 \\
\hline 10 & 0.6 & 6.0 & 31.0 & 19800 \\
\hline 11 & 0.6 & 6.6 & 33.0 & 21780 \\
\hline
\end{tabular}

\begin{tabular}{|l|l|l|l|l|}
\hline 12 & 0.6 & 7.2 & 37.0 & 23760 \\
\hline 13 & 0.6 & 7.8 & 39.0 & 25740 \\
\hline 14 & 0.6 & 8.4 & 42.0 & 27720 \\
\hline
\end{tabular}

Table 2: Values of swept area by a Street Sweeper

\begin{tabular}{|c|c|c|c|l|}
\hline $\begin{array}{c}\text { Length } \\
(\mathrm{m})\end{array}$ & $\begin{array}{c}\text { Breadth } \\
(\mathrm{m})\end{array}$ & $\begin{array}{l}\text { Swept } \\
\text { Area } \\
\left(\mathrm{m}^{2}\right)\end{array}$ & $\begin{array}{c}\text { Time } \\
\text { Taken } \\
(\mathrm{s})\end{array}$ & $\begin{array}{l}\text { Energy } \\
\text { Consumed } \\
(\mathrm{J})\end{array}$ \\
\hline 1 & 0.6 & 0.6 & 4.0 & 8800 \\
\hline 2 & 0.6 & 1.2 & 8.5 & 18700 \\
\hline 3 & 0.6 & 1.8 & 12.5 & 27500 \\
\hline 4 & 0.6 & 2.4 & 17.0 & 37400 \\
\hline 5 & 0.6 & 3.0 & 21.0 & 46200 \\
\hline 6 & 0.6 & 3.6 & 25.0 & 55000 \\
\hline 7 & 0.6 & 4.2 & 29.0 & 63800 \\
\hline 8 & 0.6 & 4.8 & 34.0 & 74800 \\
\hline 9 & 0.6 & 5.4 & 38.0 & 83600 \\
\hline 10 & 0.6 & 6.0 & 42.0 & 92400 \\
\hline 11 & 0.6 & 6.6 & 46.5 & 102300 \\
\hline 12 & 0.6 & 7.2 & 50.0 & 110000 \\
\hline 13 & 0.6 & 7.8 & 54.5 & 119900 \\
\hline 14 & 0.6 & 8.4 & 58.0 & 128700 \\
\hline
\end{tabular}

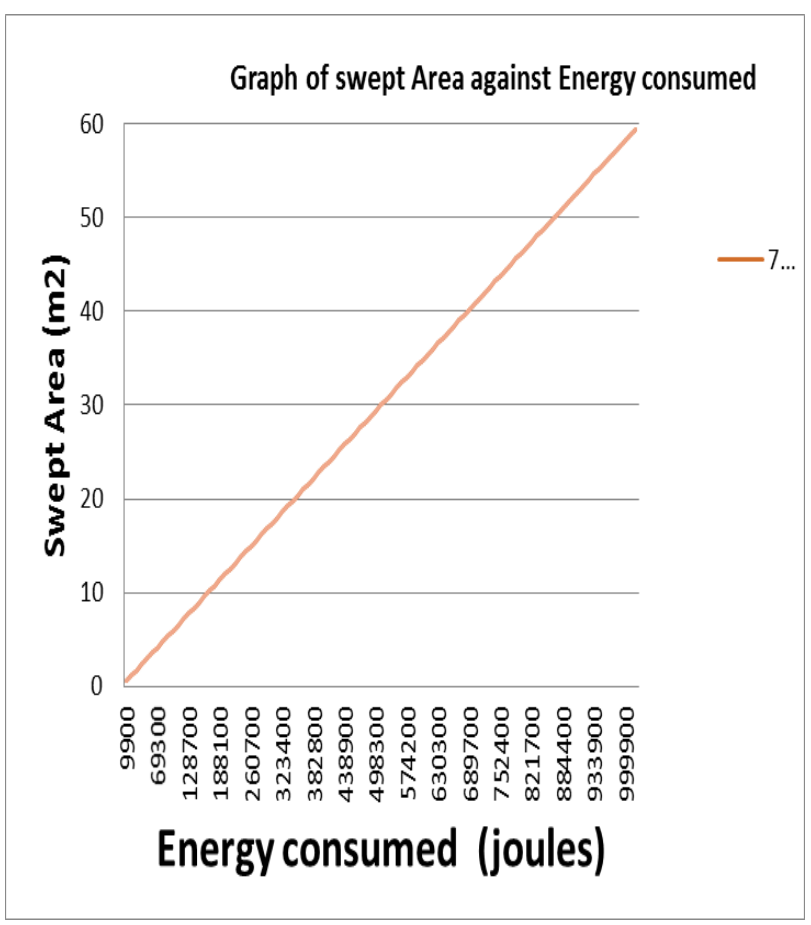

Fig 3: Swept Area against Energy Consumed

Figure 3depicted the relationship between swept area and energy consumed when 7.5hp sweeping machine developed was used. It was observed that as the swept area increased, the energy consumed by the machine also increased. This was also similar to the work of Al-Khatib et al, 2015 in which they developed a vacuum sweeper. 


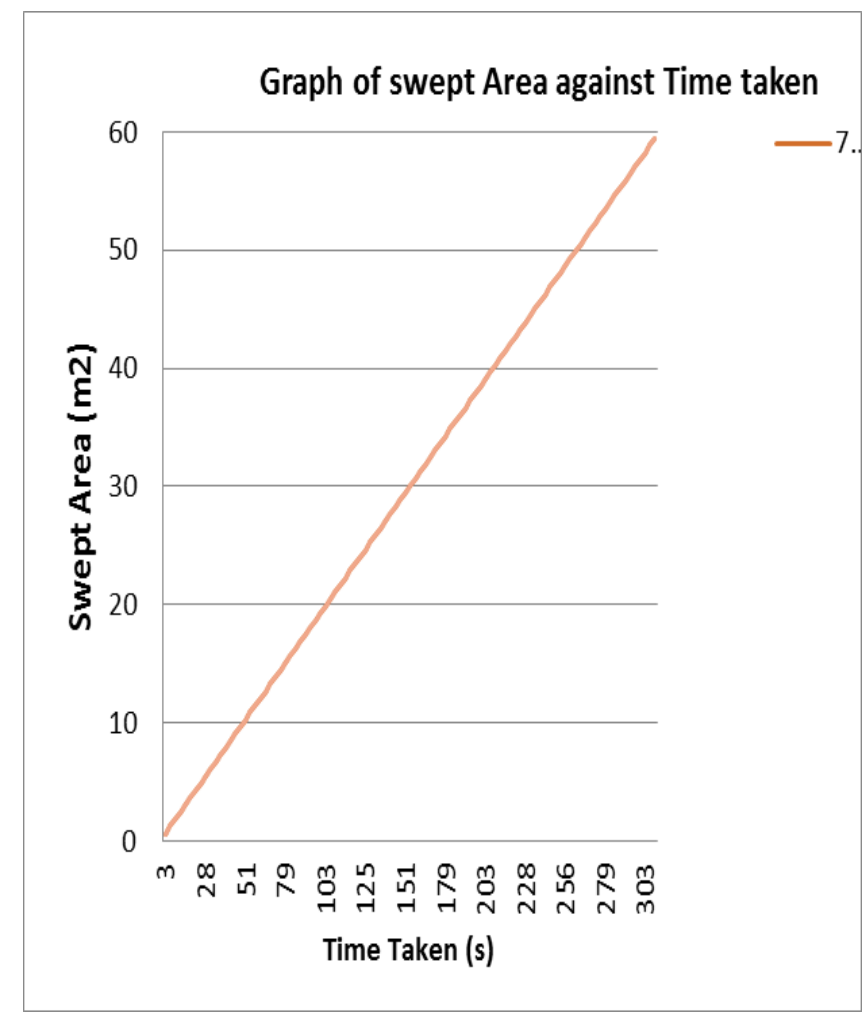

Fig 4: Swept Area against time taken- 7.5h.p Gasoline Engine

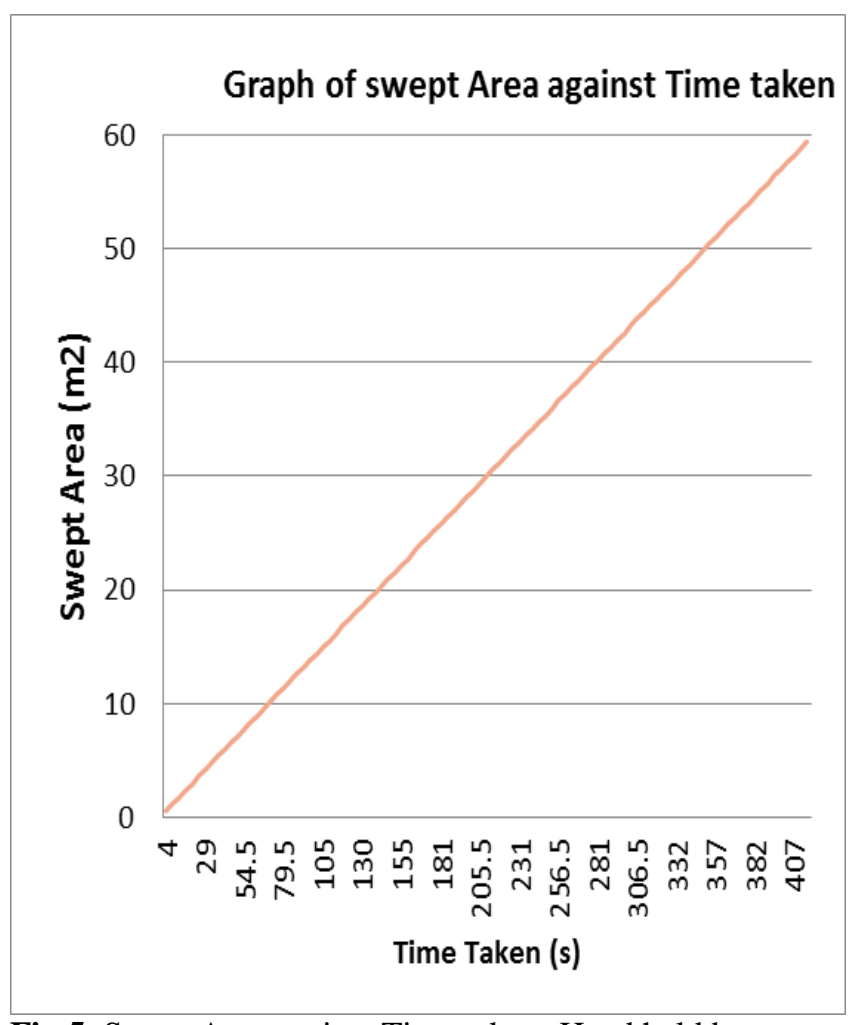

Fig 5: Swept Area against Time taken- Hand held broom
Figure 4 also showed the relationship between the swept area and time. As the swept area increased the time taken also increased. When a hand- held broom was used by a street sweeper, the time taken to sweep was higher than the time taken to sweep the same area compared to when 7.5hp was used. This is also similar to the work of Sveneson [2002] who developed an industrial brush vacuum sweeper.

\section{CONCLUSION}

Wastes are generated daily as a result of human activities in parks, garages, markets, roads thus making our environment less attractive. This portable sweeper was developed from locally available materials to suit the need and relief the difficulties associated with hand held broom sweeping task in market places. This innovative approach to market sweeping has been able to meet its intended purpose in terms of design and functionality during this Corona Virus Disease 2019 pandemic control.

\section{REFERENCES}

[1] Aluko, O. [2011] [Environmental Pollution and Waste Management, Odus Prints, Ibadan, Oyo State.

[2] Amato, F . , Querol, X and Johansson C. [ 2010] [A review of the effectiveness of street sweeping, washing and dust suppressants as urban PM control methods; Journal of Science of the total environment 23(2) 3070- 3084

[3] Bofu, W.., Jinlai M. and Chen, J[2010] Numerical study on particle removal performance of pickup head for a street vacuum sweeper, Journal of Powder Technology, 58(7). 16- 24

[4] Breault, R.F and John cart [2005] Residential Street Dirt Accumulation Rates, Chemical Composition \& Removal Efficiencies by Mechanical \& Vacuum Sweepers, New Bedford, Massachussetts

[5] Crockett. and Rajneesh S. [2014] Municipal Solid Waste Management in Ludhiana City, ITPI Journal : www.itpindia.org. pp. $62-72$

[6] Ismaila, S.O [2011], Anthropometric Data of Hand, Foot, Ear of University students in Nigeria, Leonard Journal of Sciences, Issue 15, pp 15-20

[7] Prichard. H. M, Sampson, J., and Jackson M[2009]. A further discussion of the factors controlling the distribution of $\mathrm{Pt}, \mathrm{Pd}, \mathrm{Rh}$ and $\mathrm{Au}$ in road dust, gullies, road weeper and gully flusher sediment in the city of Sheffield, UK. Journal of the Total Environment 40(7):1715-1725 


\section{International Journal of Engineering Applied Sciences and Technology, 2020 \\ Vol. 5, Issue 2, ISSN No. 2455-2143, Pages 626-630 \\ Published Online June 2020 in IJEAST (http://www.ijeast.com)}

[8] Svensson J et al [2002].Metal Content \& Particle size Distribution of Street Sediments

and Street Sweeping Wastes. Journal of Water Science \& Technology Pp46 6-7:191- 198.

[9] http://www.ntis.gov/item PB 84- 114164.

[10] http://www.enviroconmag.com/sweepers

[11] http://www.cleansweephire.co.uk

[12] http://www.greenstarmechanical.com

[13] http://www.cat.com

[14] http://www.elginsweeper.com

\section{APPENDICES}

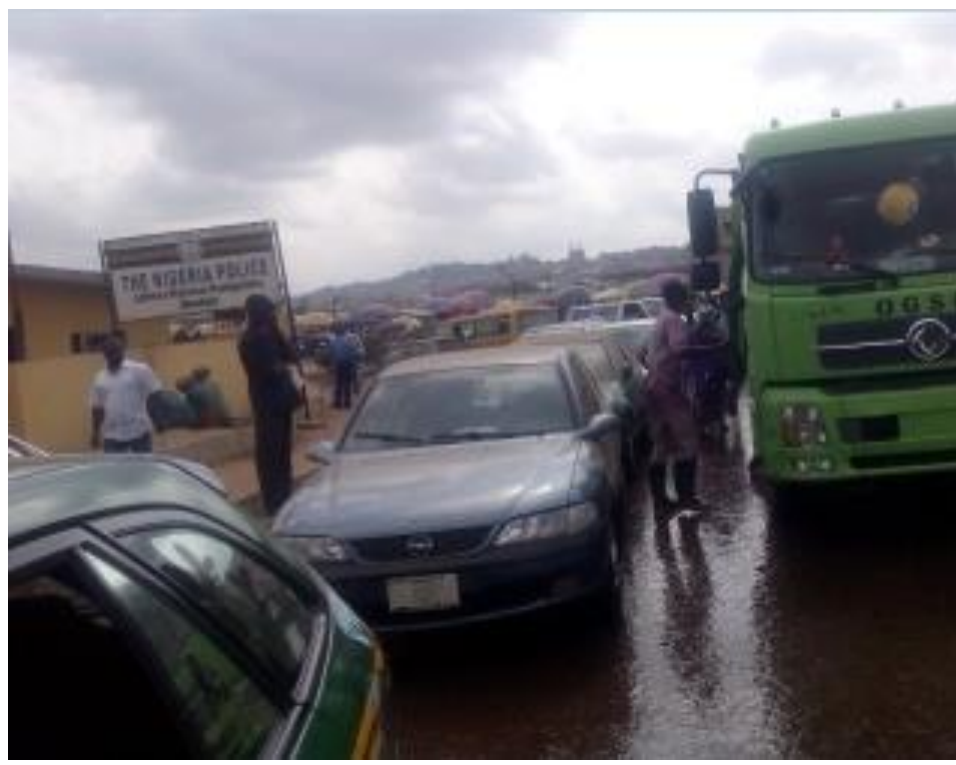

Plate 1: Market sweeping and Disinfection at Lafenwa

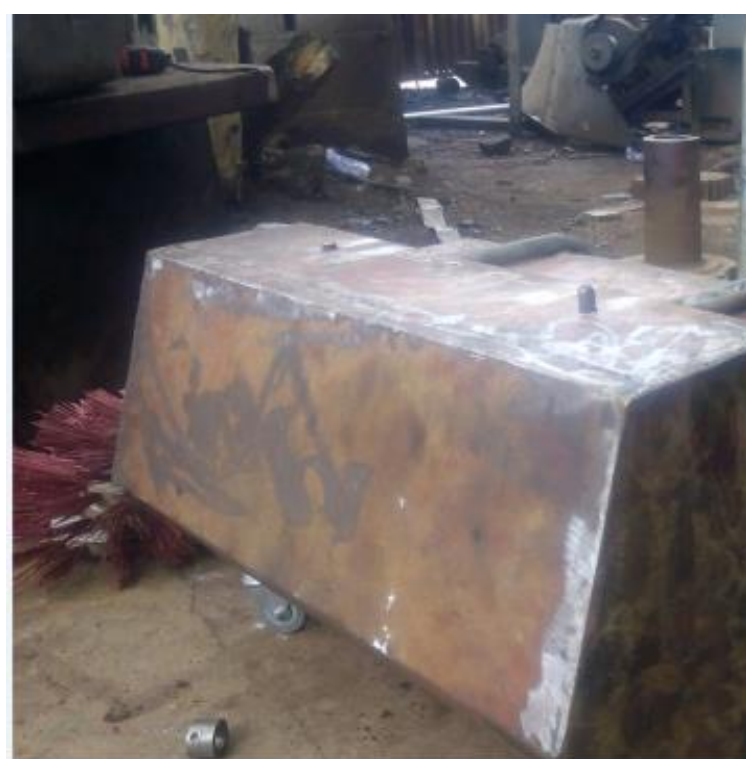

Plate 3: Hand held broom and parker sweeping of public

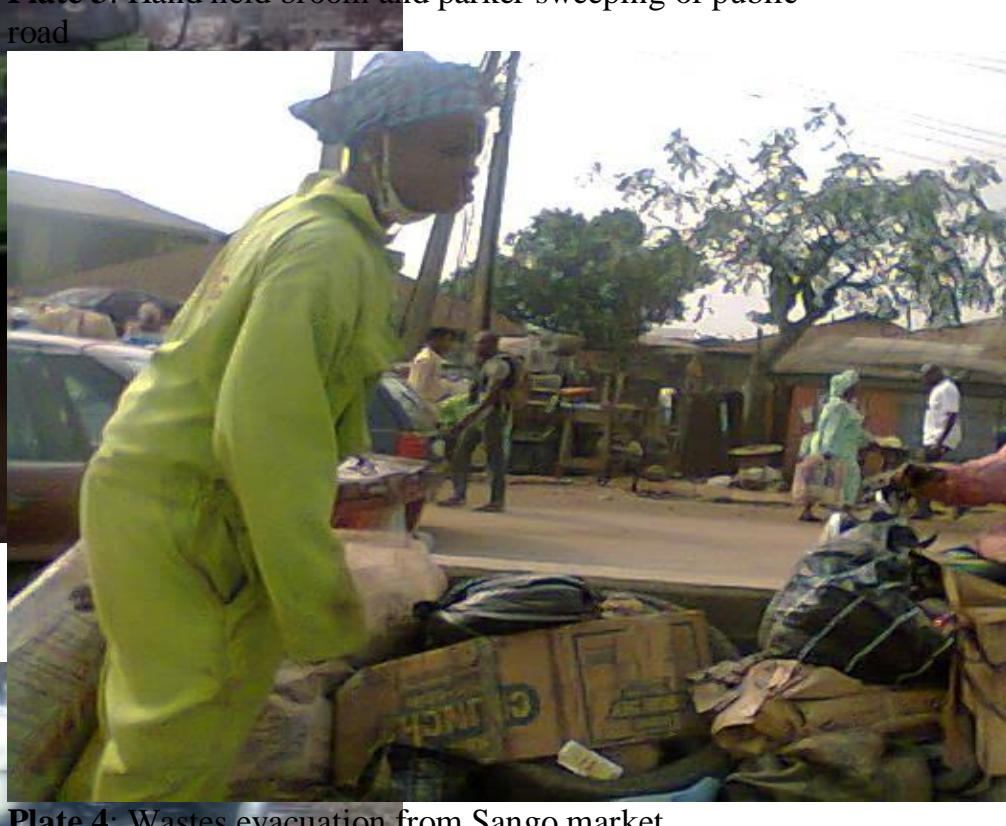

Plate 2: The fabricated portable sweeping machine

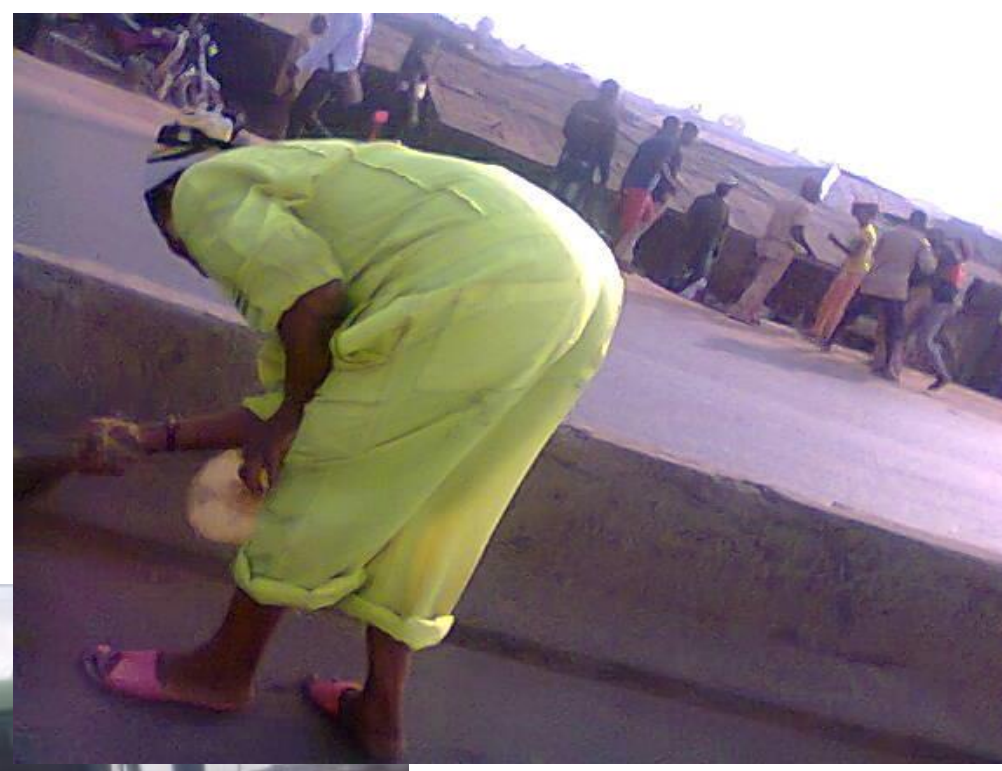

